\title{
Subsidence Analysis and Comparison between GPS Measurements and Interferometry
}

\author{
Lluís Sanmiquel ${ }^{1}$, Adrián Solorzano ${ }^{1}$, Marc Bascompta ${ }^{1}$, Josep M $^{\text {a }}$ Rossell $^{2}$, Josep Oliva ${ }^{3}$, Hernán F. \\ Anticoi $^{3}$ \\ ${ }^{1}$ Sustainable Mining \\ Polytechnic University of Catalonia (UPC) \\ Avenue Bases de Manresa, 61-73, 08242-Manresa, Barcelona \\ ${ }^{2}$ Department of Mathematics \\ Polytechnic University of Catalonia (UPC) \\ Avenue Bases de Manresa, 61-73, 08242-Manresa, Barcelona \\ ${ }^{3}$ Department of Mining Engineering, Industrial and ICT \\ Polytechnic University of Catalonia (UPC) \\ Avenue Bases de Manresa, 61-73, 08242-Manresa, Barcelona \\ lluis.sanmiquel@upc.edu; marc.bascompta@upc.edu; josep.maria.rossell@upc.edu; josep.oliva@upc.edu; \\ hernan.anticoi@upc.edu; eduard.guasch@upc.edu
}

\section{Extended Abstract}

The InSAR technology has already been applied in ground movements, demonstrating its suitability for such purpose and managing huge quantities of data. The purpose of the study is to apply the SAR interferometry in a mining area and compare the outcomes with high precision data from Global Position System (GPS).

Thirteen satellite images have been processed for such purpose, covering a time range of five years (from 2007 to 2011), with the goal to know the subsidence during this period. The specific surface features of the zone have been taken into account. GPS data has also been processed and compared, obtaining the subsidence movement in the three directions and the mean subsidence velocity per year.

The comparison between both methods show similar results in terms of subsidence generated by the underground activity, validating the suitability of InSAR by means of GPS data. However, the existence of GPS measures is crucial to calibrate and keep the necessary accuracy of the system.

\section{References}

[1] L. European Space Agency (ESA). InSAR Principles: Guidelines for SAR Interferometry Processing and Interpretation. Part A. February 2007.

[2] P. Blanco-Sánchez, J. J. Mallorquí, S. Duque, D. Monells, The Coherent Pixels Technique (CPT): An Advanced DInSAR Technique for Nonlinear Deformation Monitoring, 2008.

[3] C. Chang, J. Yen, A. Hooper, F. Chou, "Monitoring of surface deformation in northern Taiwan using DInSAR and PSInSAR techniques," Terr. Atmos. Ocean. Sci., vol. 21, no. 3, pp. 447-461, 2010. 